\title{
Play! A Special Issue
}

Caroline Bem and Susanna Paasonen

\section{$\underline{\text { Summary }}$}

Sexuality, as it relates to video games in particular, has received increasing attention over the past decade in studies of games and play, even as the notion of play remains relatively underexplored within sexuality studies. This special issue asks what shift is effected when sexual representation, networked forms of connecting and relating, and the experimentation with sexual likes are approached though the notion of play. Bringing together the notions of sex and play, it both foregrounds the role of experimentation and improvisation in sexual pleasure practices and inquires after the rules and norms that these are embedded in.

Contributors to this special issue combine the study of sexuality with diverse theoretical conceptions of play in order to explore the entanglements of affect, cognition, and the somatic in sexual lives, broadening current understandings of how these are lived through repetitive routines and improvisational sprees alike. In so doing, they focus on the specific sites and scenes where sexual play unfolds (from constantly morphing online pornographic archives to on- and offline party spaces, dungeons, and saunas), while also attending to the props and objects of play (from sex toys and orgasmic vocalizations to sensation-enhancing chemicals and pornographic imageries), as well as the social and technological settings where these activities occur. This introduction offers a brief overview of the rationale of thinking sex in and as play, before presenting the articles that make up this special issue.

$\underline{\text { Keywords }}$

Play, game studies, BDSM, sexual pleasure, pornography

\section{Foreplay: A brief overview of sex in and as play}

In 2002, Oxford University Press promoted a book by Paul R. Abramson and Steven D.

Pinkerton, With Pleasure: Thoughts on the Nature of Human Sexuality, as presenting "a controversial new theory about sexuality that proclaims the importance of pleasure over reproduction." Independent of how factual this claim may be - given that pleasure has been a key theme in much of sexuality studies, not least within feminist and queer inquiry for decades (e.g., Vance, 1989; Califia, 1994; Freeman, 2010) - it remains both striking and telling of the paradoxical status that pleasure holds within studies of sexuality. On the one hand, pleasure is an obvious motivator that pushes both individual and collective bodies in motion to reorganize zones of comfort and alignments of identity. As a theme, pleasure is 
also abundantly highlighted in the markets of sex toys, pornography, and sexual counselling. On the other hand, the complexities of pleasure remain all too easily underrepresented within much of sexuality research, be this within sexology, sex education, sociology, or cultural studies inquiry foregrounding social operations and relations of power.

This special issue starts from the simple premise that the quest for bodily pleasure is a key purpose and motivation for sexual experimentations of various kinds, from masturbation to role-play and casual hooking up. The same can be argued of play as a set of autotelic practices that do not necessarily serve any external or instrumental aims and purposes, the very enchantment of the activity being an end in itself. Bringing sexuality studies together with studies of play, this issue aims to contribute to both fields. For if play has not been a key theme in studies of sexuality, studies of play have also routinely been resistant towards the conflation of "fun-and-games" that is seen to truncate the range of stakes involved, and to possibly trivialize academic inquiry in the process (e.g., Sicart, 2004). Historically, this lack of attention given to fun, pleasure, and sex has contributed to their further marginalization as scholarly concerns, despite their centrality to how everyday lives are navigated, managed and experienced (McKee, 2016).

This trend has run parallel to a broad exclusion, or at least a long-standing marginalization, of sex and sexuality from investigations of play and playfulness, beginning with the so-called classics of game studies (Huizinga, 1949; Caillois, 2001; for a discussion, see Harviainen et al., 2016). Indeed, even within the rapidly expanding area of contemporary video game studies, it is only recently that scholars have started paying more attention to concepts such as fun and play, particularly as they relate to game design (see Mortensen, 2003; Koster, 2013; Sarkeesian and Cross, 2015; Pozo, 2018). Interest in the affect and pleasure of game 
mechanics, as well as in unruly, unwinnable, or otherwise non-conforming games, has also converged with a growingly vibrant queer gaming scene and the queer games scholarship it has sparked (Ruberg and Shaw, 2017; Harper et al., 2018; Ruberg, 2019). More recently still, these developments have been mirrored by broader research into sex within video games, as evidenced by an explosion of publications on video game sex appearing over the past five years in particular (Martinez and Manolovitz, 2010; Gallagher, 2012; Sundén and Sveningsson, 2012; Brown, 2015; Kopas, 2015; Stenros, 2015; Payne and Alilunas, 2016; Wysocki and Lauteria, 2015; Wysocki and Shook, "in preparation").

Not all sex is play, and not all sex is pleasurable, or even fun. Sex can also be work, it can feel bland, unpleasant and boring, and when people play with one another, it is at the risk of suffering or inflicting trauma. To focus on play in studies of sex does not mean undermining issues of power or vulnerability but to foreground the centrality and complexity of quests for pleasure, as well as the dynamics of experimentation and exploration that occur under more or less specified sets of agreements, rules, and terms of consent (e.g., Race, 2015). Playful, experimental encounters with other bodies - human, inanimate, technological and representational alike - afford novel horizons of possibility in terms of what bodies can do and feel, what they may enjoy, and what or who they can be (for extended discussions on sex and play, see Paasonen 2018a; Paasonen 2018b). This also means that play in the realm of sex is no light matter but, rather, one of simultaneous becoming and unbecoming, or becoming undone, where desires emerge, shift, and transform ways of making sense of the sexual self. As the testing out of possibilities of action, play helps to see how sexual tastes develop, how they are acquired, and how they morph over people's lifespans, from one situation and social connection to another, in ways almost always intangible yet no potentially dramatic. 
Thinking the notions of sex and play through each other, then, allows for focusing on specific physical sites and scenes where play unfolds - from party spaces to dungeons, bedrooms, outdoor spaces or saunas - just as it allows for zooming in on the props and objects used in play - from sex toys to pornographic inspirations and sensation-enhancing chemicals - and the social and technological settings where all this occurs. On a more fundamental level, considering sex through the analytical lens of play involves investigations into the entanglements of affect, cognition, and the senses in how sex is experienced, and in how sexual lives are lived in repetitive routines and improvisational sprees alike.

The articles presented in this special issue are developed on the basis of work presented at the Third Sexual Cultures Conference on the theme of play, held at the University of Turku in May 2019 and organized by the Academy of Finland research project Sexuality and Play in Media Culture (2017-2021), led by Susanna Paasonen. At the conference, scholars working in the (often overlapping) areas of gender and sexuality studies, screen cultures, internet research, and video game studies examined the significant parallels that exist between 1) the quest for bodily pleasure that underlies many sexual practices and 2) play, taken as a set of autotelic practices that constitute an end in themselves. The event has previously inspired a WiderScreen special issue examining sex and play in the framework of game studies (Karhulahti et al., 2020). Both continuing and expanding on these concerns, the authors in the special issue at hand investigate what follows from considering sexual representations, networked forms of relating and experimentations with sexual likes more broadly though the notion of play.

\section{Halftime: Introducing the articles}


The Third Sexual Cultures Conference: PLAY was an event as eclectic as it was electrifying: in the unending daylight of late May in Finland, it brought together established and emergent researchers hailing from different parts of Europe, Australia, New Zealand, and Canada, and working in the areas of sexuality, digital and networked culture, and video games. ${ }^{1}$

Presentation topics ran the gamut from empirical discussions of sexual pleasure to cultural studies analyses of visual representations of sex and play in online communities and their media objects. During the conference and in the debriefs that followed, organizers and participants alike referred casually to four disciplinary streams observed to run through the conference program: 1) studies of sexuality broadly speaking, either online, off, or somewhere in-between; 2) discussions of sexuality within a video game studies context; 3) pornographic cultures; and 4) studies of BDSM practices (encompassing bondage and discipline, dominance and submission, sadism and masochism, as well as other kink practices).

Commentators soon came to think of the fourth stream (BDSM) as the central conceptual bridge between the realms of sexualities scholarship and video game studies. This is unsurprising, considering that, like games, BDSM practices are rule-based. The connection has been especially noted in indie games scholarship on BDSM and other kink-oriented games (Brown, 2015; Ruberg, 2015; Navarro-Remesal and Garcia-Catalán, 2015; Lander, 2019). What is more, comparisons between BDSM/kink practices and games (Sixma, 2009; Harviainen, 2011; Faccio et al., 2016; Vossen, 2018; Sihvonen and Stenros, 2019) allow for a “challenging" and a "reimagining [of] the positions of the designer, player, and play, and what those positions mean" (Brice, 2017: 78).

\footnotetext{
${ }^{1}$ For a summary of the conference, in Finnish only, see Kauraoja 2019 (http://widerscreen.fi/numerot/ajankohtaista/sexual-cultures-konferenssi-turussa-28-29-5/). The conference website featuring English abstracts is available at https://blogit.utu.fi/sexualcultures/.
} 
In keeping with the place BDSM and other kink practices occupied within the Sexual Cultures conference roster, two out of the seven contributions selected for this special issue focus explicitly on BDSM, while several others make references to this set of practices. Titled "'My Games are... Unconventional’: Intersections of game and BDSM studies," Tanja Sihvonen and J. Tuomas Harviainen's article offers a comparatist overview of BDSM studies as a central point of contact between the fields of game studies and sexuality studies. By focusing on the mechanics of gameplay rather than on game aesthetics, the authors are able to identify five separate strands - 1) Direct comparisons, 2) Live-action role-playing, 3) Adaptive ethics and practices, 4) Queer games studies, and 5) Games, performance and rituals - where BDSM and games overlap. Through this typology, the article adroitly interweaves a consideration of embodied sexual practices and gaming with a valuable metacommentary on the theoretical dialogue between studies of sexuality and game studies.

While Sihvonen and Harviainen privilege a broad viewpoint, Jordana Greenblatt's autoethnographic article "Aerial, apparatus, assemblage: Pain, pleasure, kink, and the circus body without organs" draws on concepts ranging from Deleuze's body without organs $(\mathrm{BwO})$ to Agamben's apparatus, as well as on recent writings on play, pain, pleasure, and the circus body. By conflating their experiences as both an aerialist and a BDSM practitioner, Greenblatt highlights how, through the notion of play, the combined experience of BDSM practice and circus aerial shines a new light on the BwO's relation to control and abandon. Thus, where in Sihvonen and Harviainen's article, play serves as a conceptual link between different embodied and disciplinary understandings of BDSM, in Greenblatt's case study, play acts as both a unifying and a destabilizing concept that allows for a more nuanced reading of self-inflicted pain than traditional theories of masochism would suggest. 
Sihvonen and Harviainen's contribution, as well as Greenblatt's article, make visible that, while rule-based logic is a natural place to begin theorizing the intersections of sex and games, a turn to play in both sex and games studies opens the door to nuanced reconceptualizations of somatic and affective pursuits (desire, pain, intensity) and ethical stakes (consent, control, relationality) as these play out and take hold in the sexual realm. In particular, play further destabilizes the always-already-fuzzy boundary between practices considered vanilla and kink. Across their widely diverse topics and objects of study, which range from online pornography usage in Turkey to the data-mining of sex toy users across the globe and the place of pornography in the spatial and social arrangements of men's saunas in South Korea and Taiwan, the issue's five remaining contributions centre sexual practices that could, in many contexts, be characterized as kinky or kink-adjacent, but which, when framed through the notion of play, are explored without seeking to categorize them in any particular way.

When play becomes the central lens through which sexual practices are apprehended, attention shifts the granularity of acts, affects, and rituals in ways that forego any need for necessarily normative categorization - be this in terms of hierarchies of sexual normalcy (Rubin, 1989) or in terms of taxonomical notions of sexual preference and identity. Understood as experimentations that move and transform bodies and their desires, play helps in thinking beyond binary distinctions drawn between the straight and the queer, the vanilla and the kink, where the former notion both points to a social norm and indicates fixity in terms of what bodies can be, do, and want. Classic theorizations of play address sex in the context of "illicit sex relationships"; "casual, abnormal, or strange sex practices" (Caillois, 2001: 27, 34) and "erotic relationships falling outside the social norm" (Huizinga, 1949: 43). 
Within such boundary work, the playfulness of non-normative sex is mapped out against that which is not playful, just as fluidity only makes sense in relation to that which is considered fixed (Ahmed, 2000: 84). Broadening considerations of sex and play beyond such binary logic offers solutions to the risk of replicating a morally weighed views pertaining to both kink and vanilla: instead, experimentation and transformation, or at least the potentiality thereof, is associated with all kinds of sexual practices. Play, as the following articles show, helps in accounting for the breadth of sexual practices and their contradictions in context.

Such contextual nuance is key to Shawn Suyong Yi Jones's article, "Play by design: The porn-viewing room in Taiwanese and Korean men's sex saunas," which focuses on the broadly infrastructural arrangements set out for sexual play. Drawing an analogy between the sauna and the playground, Jones attends to the spatial arrangements of screens, seats, and mats, as well as to the kinds of pornography that they feature in order to map out the overall scene of play and its rules that are then appropriated and improvised upon by the men frequenting the premises studied. The main focus of the article is then not on how men play in these spaces but, rather, on how they are invited and encouraged to interact, gather and spend time within them, as well as on the role that gay porn - in its designed visibility and invisibility as it connects to its availability, and as it is controlled by local legislation - plays in all this. Moving from both explicit and subtle cultural codes and sexual norms to more ambiguous spatio-sexual solutions, Jones's analysis remains attuned to context, and ambitious in mapping out the materially and socially precarious conditions of sexual relating.

Contra Jones' focus on the physical settings and designs of play, Aljoša Pužar's 'Soundtracks of human mimetic sexual play: The case of East Asian regional sexual vernacular" explores the soundscapes of sexual "faking" and reenactment within a South Korean context through 
intimate narratives. Applying the notion of play to his ethnographic engagement with sexual soundscapes allows Pužar to simultaneously explore and complicate the dominant assumption that pornography serves as a primary source of "mimetic moaning." As the author argues, the soundtracks in question "depend on two extremes of how resonance is conceptualized in the field of play": first, they function as affective resonances (Paasonen, 2011), but they also "abide by precise conditions of systemic resonance described within Csikszentmihalyi's exploratory model of play" (Csikszentmihalyi and Bennett, 1971). By adapting concepts from scholarship on play to his analysis, Pužar aptly reveals the complex layers of mimetic play that undergird the soundscapes in question, revealing more nuanced and complex forms of looping to be at work between pornography and lived sexual practices.

In ““Any performer you pick!' Playful manifestations of porn spectatorship,” Ihsan Asman examines the experiences of online pornography spectatorship of 18 Turkish young adults in their 20s and 30s. Against the (largely unspoken) backdrop of severe political and social unrests, and of evolving restrictions on pornography and sexual expression, all due to the rise of Recep Tayyip Erdogan's conservative, Islamist Justice and Development Party (AKP), the subjects of Asman's interviews speak very openly of their affective and embodied engagements with online pornography. Asman argues that, in the hands of his subjects keen to experiment with sexuality, pornography becomes akin to a toy which, following Miguel Sicart, Asman defines as "an opening for appropriation" and "an extension of the playful mind" (Sicart, 2014: 40). Ultimately, this reconceptualization of pornography as a toy allows Asman to move away from fixed identity categories in his analysis of his subjects' complicated engagements with online pornography and the multiplicity of ways these are lived out. 
Echoing approaches and concerns present in the previous contributions, yet also expanding upon them, the article "Hanging, blowing, slamming and playing: Erotic control and overflow in a digital chemsex scene," by Kristian Møller, focuses on methamphetamine use within the context of a large, week-long Zoom online event. The author collected his empirical research data a year before the COVID-19 pandemic broke out, in retrospect foreshadowing how the format and platforms of large-scale online events long used within BDSM and other sexual subculture communities would soon become essential to socializing and playing in groups within the mainstream. Drawing from his extensive fieldnotes, Møller adopts an affective-materialist approach to chemsex that goes against critical health perspectives that tend to highlight the practice's detrimental aspects. Both his focus on digital chemsex and his theoretical framework, enable him to engage with parameters beyond risk and health. Discussing the role played by smoke itself within the iconography of the online gathering, Møller argues that users' recurring fetishization of crystal meth smoke displaces the scene's investments in the "body and its gay coding" onto a form of aesthetic engagement "where identity cannot fully account for the spectacle." In this way, smoke and the drug use it signifies become an impossible-to-categorize "plaything" not dissimilar from the toy-status which Asman attributes to pornography as a whole.

Finally, zooming into physical objects of sexual play, and bringing together multiple strands of conversation cutting through the special issue, Jenny Sundén's contribution, "Play, secrecy and consent: Theorizing privacy breaches and sensitive data in the world of networked sex toys," explores the problems posed by the recording of users' play sessions with digital sex toys. Looking to queer BDSM cultures in particular, the author articulates how the trifecta of privacy-intimacy-safety has been taken for granted within the mainstream and is now being significantly complicated by the intrusion into private bedrooms of networked sex toys and 
the public platforms they connect to. By approaching networked sex toys through a new materialist framework, Sundén is able to look beyond understandings of agency that are typically limited to human subjects. Consequently, her analysis explores central issues, such as big data and digital privacy, through the prism of (non-normative) sexual intimacy and play, allowing the author to make the case for a "feminist data politics" that would transcend the use of consent as a primary legal framework so as to include questions of intimacy, pleasure, and accessibility within its language.

\section{$\underline{\text { Endgame }}$}

Taken individually, none of the articles that make up this special issue has the pretention to offer a generalized theory of the place of play within sexual practice, nor is this precisely our collective aim, either. Considered in their totality, these seven articles showcase a number of ways in which conceptualizations of play allows us to break wide open how we approach and make sense of the diverse social, spatial, and material parameters of sexual encounters, as well as of the narratives of pleasure and desire connected to sexual experimentation that they spawn. "Play! A special issue" foregrounds playfulness within the realm of sexuality as something to be nurtured and protected, but also as a theoretical lens analytically rigorous enough to account for the banal and extraordinary, routine and spectacular variations of sexual practices on levels both social and highly personal.

\section{$\underline{\text { References: }}$}

Ahmed, S (2000) Strange Encounters: Embodied Others in Post-Coloniality. London: Routledge.

Brice, M (2017) Play and be real about it: What games could learn from kink. In: Ruberg, B, Shaw, A (eds) Queer Game Studies. Minneapolis: University of Minnesota Press, pp. $77-82$.

Brown, AML (2015) Sexuality in Role-Playing Games. New York and London: Routledge. 
Caillois, R (2001) Man, Play and Games. Urbana: The University of Illinois Press.

Califia, P (1999) Public Sex: The Culture of Radical Sex. Second Edition. San Francisco: Cleis Press

Csikszentmihalyi, M, Bennett, S (1971) An exploratory model of play. American Anthropologist 73 (1): 45-58.

Faccio, E, Casinia, C, Cipolletta, S (2016) Forbidden games: The construction of sexuality and sexual pleasure by BDSM 'players'. Culture, Health \& Sexuality 16 (7): 752764.

Freeman, E (2010) Time Binds: Queer Temporalities, Queer Histories. Durham, NC: Duke University Press.

Gallagher, R (2012) No sex please, we are finite state machines: On the melancholy sexlessness of the video game. Games and Culture 7 (6): 399-418.

Harper, T, Blythe Adams, M, Taylor N (eds.) (2018) Queerness in Play. New York: Palgrave Macmillan.

Harviainen, JT (2011) Sadomasochist role-playing as live-action role-playing: A traitdescriptive analysis. International Journal of Role-Playing 2: 59-70.

Harviainen, JT, Brown, AML, Suominen, J (2016) Three waves of awkwardness: A metaanalysis of sex in game studies. Games and Culture 13(6): 605-623.

Huizinga, J (1949) Homo Ludens: A Study of the Play-Element in Culture. London: Routledge and Kegan Paul.

Karhulahti, VM, Saarenmaa L, Brown AML (eds) (2019) Sexuality and Play. WiderScreen 22 (1-2) : http://widerscreen.fi/numerot/2019-1-2/.

Kauraoja, V (2019) Sexual Cultures - konferenssi Turussa 28-29.5. WiderScreen 22 (1-2). http://widerscreen.fi/numerot/ajankohtaista/sexual-cultures-konferenssi-turussa-2829-5/

Kopas, M (2015) Ludus interruptus: Video games and sexuality. In: Goldberg D, Larsson L (eds) The State of Play: Creators and Critics on Video Game Culture. New York: Seven Stories Press, pp. 211-233.

Koster, R (2013) A Theory of Fun for Game Design, $2^{\text {nd }}$ ed. Sebastopol, CA: O'Reilly Media.

Lander, M (2019) PowerGaming: Queer BDSM and Weird Little Games. Master's Thesis, OCAD University, Canada.

Martinez, M, Manolovitz, T (2010) Pornography of gaming. In: Riha, D (ed.) Video Game Cultures and the Future of Interactive Entertainment. Interdisciplinary Press, pp. 6574.

McKee, A (2016) FUN! What Entertainment Tells Us About Living a Good Life. London: Palgrave.

Mortensen, TE (2003) Pleasures of the Player: Flow and Control in Online Games. PhD Thesis, University of Bergen, Norway.

Navarro-Remesal, V, Garcia-Catalán, S (2015) Let's play master and servant: BDSM and directed freedom in game design. In: Wysocki, M, Lauteria, E (eds) Rated M for Mature: Sex and Sexuality in Video Games. New York: Bloomsbury, pp.119-131.

Paasonen, S (2011) Carnal Resonance: Affect and Online Pornography. Cambridge, MA: MIT Press.

Paasonen, S (2018a) Many Splendored Things: Thinking Sex and Play. London: Goldsmiths University Press.

Paasonen, S (2018b) Many splendored things: Sexuality, playfulness and play. Sexualities 21 (4): 537-551.

Payne, MT, Alilunas, P (2016) Regulating the desire machine: Custer's revenge and 8-bit Atari porn video games. Television \& New Media 17 (1): 80-96. 
Pozo, T (2018) Queer games after empathy: Feminism and haptic game design aesthetics from consent to cuteness to the radically soft. Game Studies 18 (3): http://gamestudies.org/1803/articles/pozo.

Race, K (2018) The Gay Science: Intimate Experiments with the Problem of HIV. New York: Routledge.

Ruberg, B, Shaw, S (eds.) (2017) Queer Game Studies. Minneapolis: University of Minnesota Press.

Ruberg, B (2015) Pixel Whipped: Pain, Pleasure, and Media. PhD Thesis, UC Berkeley, USA.

Ruberg, B (2019) Video Games Have Always Been Queer. New York: NYU Press.

Rubin, G (1989) Thinking sex. In: Vance, CS (ed) Pleasure and Danger: Exploring Female Sexuality. London: Pandora, 267-319.

Sarkeesian, A, Cross, K (2015) The state of play: Creators and critics on video game culture. In: Goldberg D, Larsson L (eds) The State of Play: Creators and Critics on Video Game Culture. New York: Seven Stories Press, pp. 103-126.

Sicart, M (2014) Play Matters. Cambridge: MIT Press.

Sihvonen, T, Stenros, J (2019) Queering games, play, and culture through transgressive roleplaying games. In: Jørgensen, K, Karlsen, F (eds) Transgression in Games and Play. Cambridge: MIT Press, pp.115-129.

Sixma, T (2009) The Gorean community in Second Life: Rules of sexual inspired role-play. Journal of Virtual Worlds Research 1(3).

Stenros, J (2015) Playfulness, Play, and Games: A Constructionist Ludology Approach. PhD Thesis, University of Tampere, USA.

Sundén, J, Sveningsson, M (2012) Gender and Sexuality in Online Game Cultures: Passionate Play. London: Routledge

Vance, CS S. 1989. Pleasure and danger: Towards a politics of sexuality. In: Vance, CS (ed) Pleasure and Danger: Exploring Female Sexuality. London: Pandora, 1-27.

Vossen, E (2018) The magic circle and consent in gaming practices. In: Gray, K, Voorhees, G, Vossen, E (eds) Feminism in Play. Cham: Palgrave Macmillan.

Wysocki, M, Lauteria, EW (eds) (2015) Rated M for Mature: Sex and Sexuality in Video Games. New York: Bloomsbury.

Wysocki, M, Shook, S (eds) (in preparation) Handbook on Games and Sex/Sexuality. London: Bloomsbury Publishing. 